\title{
Awareness of adverse drug reactions reporting among doctors in a tertiary care centre
}

\author{
Laila K. V., Hemalatha T.*
}

Department of Pharmacology, Calicut Medical College, Kozhikode, Kerala, India

Received: 04 August 2016 Accepted: 03 September 2016

\section{*Correspondence to:}

Dr. Hemalatha T,

Email: hemalini11@gmail.com

Copyright: (c) the author(s), publisher and licensee Medip Academy. This is an openaccess article distributed under the terms of the Creative Commons Attribution NonCommercial License, which permits unrestricted noncommercial use, distribution, and reproduction in any medium, provided the original work is properly cited.

\begin{abstract}
Background: Adverse drug reactions (ADR) are more commonly observed during treatment course in a substantial number of patients. Though we have a functioning pharmacovigilance programme in India, we have only fewer number of adverse drug reactions being reported indicating lack of awareness, the unsure attitude and reluctance in reporting adverse drug reactions.

Methods: We conducted a cross sectional pretested questionnaire based study for a period of six months. 600 questionnaires were distributed. 521 responded back to the questionnaire of which $29.6 \%$ were interns, $56.8 \%$ were junior residents, 5.2\% doctors were senior residents, and $8.4 \%$ were Assistant professors. Awareness on ADR reporting, ADRs encountered in practice, common causative drugs for ADR, and awareness on the functions of Pharmacovigilance programme of India were assessed.

Results: $44.9 \%$ were not aware of the pharmacovigilance programme; $59.5 \%$ of the study population were not aware of the voluntary reporting of ADRs. 100\% of the doctors who participated actively in the study responded that have not reported any ADR so far under pharmacovigilance programme of India. 88.1\% of the doctors who participated in the study were willing to undergo a training on ADR reporting and pharmacovigilance.

Conclusions: This study concludes that serious measures have to be taken to educate the doctors on ADR reporting and pharmacovigilance. By means of involving pharmacovigilance as a part of the undergraduate programme and by organising regular workshops, group discussion and continuous medical education, we can improve the awareness among doctors regarding ADR reporting and pharmacovigilance.
\end{abstract}

Keywords: ADR, Pharmacovigilance, Awareness

\section{INTRODUCTION}

Adverse drug reactions are more commonly observed during the course of therapy in a substantial number of patients. ADRs are one of the important causes of morbidity and mortality worldwide. ${ }^{1}$ WHO defines adverse drug reaction as "any noxious, unintended and undesired effect of a drug, which occurs at doses used in humans for prophylaxis, diagnosis or therapy". This definition excludes therapeutic failures, intentional and accidental poisoning (i.e. overdose and drug abuse). ${ }^{2}$

Newer medicines have an improved mechanism of action for diseases in which they are used. However, in spite of their benefits, evidence suggests that adverse reactions to medicines are common, yet often preventable. The prevalence of ADR in India is $16.2 \% .^{3}$ To overcome this problem of adverse drug reactions, the Ministry of Health and Family Welfare, Govt. of India, has initiated the National Pharmacovigilance Programme. Pharmacovigilance is by definition "the science and activities which are related to the detection, assessment, understanding and the prevention of adverse effects or any other drug related problems". The purpose of this programme is to collect the data, analyse and use the outcome of the data to recommend well informed regulatory interventions, and also communicating the risks to the health care professionals and to the public. The pharmacovigilance programme is coordinated by the National Pharmacovigilance Centre at the Central Drugs Standard Control Organization in New Delhi. The National Centre is operating under the supervision of the 
National Pharmacovigilance Advisory Committee, to recommend the procedures and guidelines for regulatory interventions. ${ }^{5}$

Under Pharmacovigilance programme of India, Voluntary reporting stays to be the most important methods of surveillance of ADRs. Voluntary reporting system in which the ADR forms are filled by the physicians, pharmacists and also the patients, who are consumers, to report suspected ADRs to a pharmacovigilance centre.,

\section{METHODS}

The study design was a cross sectional questionnaire based study.

The setting of this study was conducted at the Government Medical College, Kozhikode. This is one of the oldest medical colleges in Kerala started in 1954.

The study was approved by the Institutional Ethics committee, Government Medical College, Kozhikode.

\section{Study population}

This study was a non-interventional study done among the doctors in whom interns, junior residents, senior residents and Assistant professors participated. Those who were not willing to participate and those who did not return the questionnaires in the stipulated time were excluded from the study.

The study tool was a pretested closed end questionnaire which was designed to assess the awareness of adverse drug reaction reporting among the doctors at Government medical college, Kozhikode.

\section{Study procedure}

All the doctors who were willing to participate in the study were administered the questionnaire. The participants were briefed about the questionnaire. The participants were given 30 minutes to answer the questionnaire and they were not allowed to consult anyone during that time. They could maintain anonymity with regards to their names, but they had to write their designations. The answers to the questions were not mutually exclusive. They were requested to return the duly filled in forms at the end of 30 minutes. The questionnaires were then evaluated and were analysed by SPSS version 18.0

\section{RESULTS}

A total of 600 questionnaires were distributed out of which 521 responded back to the questionnaire. Among 521 doctors who responded, $29.6 \%$ were interns who were undergoing their house surgeon ship, $56.8 \%$ were junior residents, $5.2 \%$ doctors were senior residents, and $8.4 \%$ were assistant professors.
Awareness of adverse drug reaction reporting as to who has to report was assessed. $18.6 \%$ of the study population responded that it is the duty of the doctors to report ADRs; $68.3 \%$ responded that all health care professionals are qualified to report ADRs; $4.6 \%$ responded that only doctors and nurses are qualified to report ADRs; $4 \%$ responded that pharmacists are qualified to report the ADRs; $4.4 \%$ of the study population have no opinion on who has to report ADRs.

$77.7 \%$ of the doctors who participated actively in the study responded that their patients had experienced ADR at least once in their lifetime whereas $22.3 \%$ of the study population responded that their patients have not experienced any ADRs so far. Regarding the frequency of encountering ADRs in practice, $15.9 \%$ of the doctors had encountered ADRs often in their practice, while $13.8 \%$ of the doctors encountered ADRs very rarely, $60.8 \%$ of the doctors encountered ADRs occasionally while $9.4 \%$ of the study population did not respond this question. Common drugs most likely to produce ADRs were assessed from the questionnaire; Based on the response from the study population it was found that that $59.7 \%$ of ADRs may be associated with any drug, whereas new drugs and vaccines were suspected to cause about $19 \%$ of the ADRs, antibiotics suspected for $38.4 \%$ of ADRs while $1.9 \%$ of the study population did not respond.

$55.1 \%$ of study population were aware of the existence of a functional national pharmacovigilance programme and $44.9 \%$ were not aware of the pharmacovigilance programme. Regarding the location of National Pharmacopoeia Commission, only $34.2 \%$ of the study population responded correctly that it is located in Ghaziabad. $40.5 \%$ of the study population were aware of the ADR reporting form whereas $59.5 \%$ of the study population were not aware of the voluntary form for reporting ADRs. And also $100 \%$ of the doctors who participated and responded to the questionnaire have not reported any ADR so far under Pharmacovigilance Programme of India.

Attitudes on reporting ADR was assessed in which it was found that $63.7 \%$ of the study population felt that ADRs could not be reported due to lack of time to actively look for ADRs while at work $10.9 \%$ of study population felt that the report being wrong, $7.7 \%$ felt that ADRs could not be reported promptly due to lack of time, $6.7 \%$ felt that ADRs are not reported due to non-remuneration for reporting, $3.1 \%$ felt that reporting an ADR might generate extra work, $6.5 \%$ felt that there was no need to report a recognised ADR. $64.3 \%$ of the study population felt that ADR reporting to be made compulsory whereas $20 \%$ of the study population felt that ADR reporting should be voluntary, while $15.7 \%$ felt that ADR reporting should be remunerated.

$88.1 \%$ of the doctors who participated actively in the study were willing for training on how to report an ADR 
Table 1: Questionnaire results.

\begin{tabular}{|c|c|}
\hline Entity & Results \\
\hline \multirow{2}{*}{ No. of questionnaires } & Distributed - 600 \\
\hline & Filled - 521 \\
\hline \multirow{4}{*}{ Study population } & Interns - $29.6 \%$ \\
\hline & Junior residents - $56.8 \%$ \\
\hline & Senior residents - $5.2 \%$ \\
\hline & Assistant professors $-8.4 \%$ \\
\hline \multirow{5}{*}{ Awareness on who has to report an ADR } & Doctors: $18.6 \%$ \\
\hline & All health care professionals $-68.3 \%$ \\
\hline & Doctors and nurses $-4.6 \%$ \\
\hline & Pharmacist - 4\% \\
\hline & No opinion - $4.4 \%$ \\
\hline \multirow{2}{*}{ Whether experienced ADR in lifetime? } & Yes $-77.7 \%$ \\
\hline & No $-22.3 \%$ \\
\hline \multirow{4}{*}{ ADR frequency encountered in practice } & Often $-15.9 \%$ \\
\hline & Very rarely $-13.8 \%$ \\
\hline & Occasionally - $60.8 \%$ \\
\hline & No response $-9.4 \%$ \\
\hline \multirow{4}{*}{ Common drugs causing ADR } & Any drug $-59.7 \%$ \\
\hline & Antibiotics $-38.4 \%$ \\
\hline & New drugs and Vaccines - $19 \%$ \\
\hline & No response $-1.9 \%$ \\
\hline \multirow{2}{*}{$\begin{array}{l}\text { Awareness on existence of pharmacovigilance programme of } \\
\text { India }\end{array}$} & Aware $-55.1 \%$ \\
\hline & Unaware $-44.9 \%$ \\
\hline \multirow{2}{*}{ Location of National pharmacopoeia commission } & Correct (Ghaziabad) $34.2 \%$ \\
\hline & Incorrect - $65.8 \%$ \\
\hline \multirow{2}{*}{ Aware about voluntary reporting form for ADRs } & Aware -40.5 \\
\hline & Unaware $-59.5 \%$ \\
\hline \multirow{2}{*}{ Reported any ADR so far? } & Yes - $0 \%$ \\
\hline & No $-100 \%$ \\
\hline \multirow{7}{*}{ Reason for under reporting } & Lack of time to look for an ADR - $63.7 \%$ \\
\hline & Lack of time to report a recognized ADR $-7.7 \%$ \\
\hline & Report might be wrong - $10.9 \%$ \\
\hline & Non remuneration for reporting $-6.7 \%$ \\
\hline & Generates extra work $-3.1 \%$ \\
\hline & Not needed to report an ADR - $6.5 \%$ \\
\hline & No response $-1.4 \%$ \\
\hline Willing for training in pharmacovigilance & Yes $-88.1 \%$ \\
\hline
\end{tabular}

\section{DISCUSSION}

India has one of the largest drugs consuming population, with majority of people belonging to low socioeconomic group. Thus, it is the need of the hour to identify adverse drug reactions as early as possible in order to prevent them if possible, for ensuring the well-being of the patient at reasonable cost. ${ }^{8}$ In common, drugs and any other substances that is capable of producing a therapeutic effect may also lead to adverse effects which may range from mild to lethal adverse effects." "There are 3 actions of a drug: the one you want, the one you don't want, and the one you don't know about". ${ }^{10}$
In India, the pharmacovigilance related activities were started early in 1986. But it was not successful due to technical issues. Later Ministry of Health and Family Welfare, Government of India, launched the Pharmacovigilance Program of India (PvPI) in July 201011. Pharmacovigilance can survive only on spontaneous reporting by the healthcare professionals, which in turn depends on their good knowledge about pharmacovigilance as well as their willingness to report. ${ }^{8}$ Many factors are related to the adverse drug reaction under reporting among the doctors. But basically, in order to improve the reporting rate, it is important to educate the doctors regarding ADR reporting as well as pharmacovigilance. 
This study evaluated the awareness of adverse drug reaction reporting among the interns, junior residents, senior residents and assistant professors of a Government teaching hospital. Many Indian studies were conducted evaluating the Knowledge, attitude and awareness on adverse drug reaction reporting among health care professionals. These studies revealed that the awareness on adverse drug reaction reporting among the doctors is very low owing to the poor knowledge on Pharmacovigilance practice activities. ${ }^{12-15}$

Our study was in accordance with the above mentioned studies. In our study $44.9 \%$ were not aware of the Pharmacovigilance programme; $59.5 \%$ of the study population were not aware of the voluntary form for reporting ADRs. $100 \%$ of the doctors who participated actively in the study responded that have not reported any ADR so far under pharmacovigilance programme of India. $88.1 \%$ of the doctors who participated in the study were willing to undergo a training on ADR reporting and pharmacovigilance.

These observations suggest the need to incorporate ADR reporting and pharmacovigilance based education in their undergraduate training programme. A good theoretical knowledge on ADR reporting and pharmacovigilance can be incorporated in the students by adding these topics in their syllabus and also practical knowledge can be sought by visiting the nearest Pharmacovigilance centre and training them in the data handling activities. Seminars, group discussion and continued medical education programmes can also serve as a means of educating the doctors on ADR reporting. As a result, students as doctors can realise that medicines are meant to save lives as most of the ADRs are often preventable. This also helps to realise that reporting an ADR also contributes significantly to the healthcare system and also reduce the economic burden to the consumers by bringing proper regulatory interventions.

\section{ACKNOWLEDGEMENTS}

Authors would like to thanks all the participants involved in this study.

Funding: No funding sources

Conflict of interest: None declared

Ethical approval: The study was approved by the Institutional Ethics Committee

\section{REFERENCES}

1. $\mathrm{Wu} \mathrm{W}$, Pantaleo N. Evaluation of outpatient adverse drug reactions leading to hospitalization. American
Journal of Health-System Pharmacy. 2003;60(3):2539.

2. WHO. International Drug Monitoring: The Role of the Hospital. Geneva, Switzerland: WHO; Technical Report Series No 425; 1966.

3. Haile DB, Ayen WY, Tiwari P. Prevalence and assessment of factors contributing to adverse drug reactions in wards of a tertiary care hospital, India. Ethiop J Health Sci. 2013;23(1):39-48.

4. The World Health Organization. Safety of Medicines: A guide for detecting and reporting adverse drug reactions. Geneva; WHO / EDM / QSM; 2002:2.

5. Prakash S. Pharmacovigilance in India. Indian $\mathrm{J}$ Pharmacol. 2007;39:123.

6. Van Grootheest K, de Jong-van D. Patients' role in reporting adverse drug reactions. Expert Opin Drug Saf. 2004;3(4):363-8.

7. Van Grootheest K, Olsson S, Couper M. Pharmacists role in reporting adverse drug reactions in an international perspective. Pharmacoepidemiol Drug Saf. 2004;13(7):457-64.

8. Bisht $M$, Singh S, Dhasmana DC. Effect of educational intervention on adverse drug reporting by physicians: a cross-sectional study. Hindawi Publishing Corporation ISRN Pharmacology. 2014:8:Article ID 259476.

9. Abubakar AR, Simbak NB, Haque M. A systematic review of knowledge, attitude and practice on adverse drug reactions and pharmacovigilance among doctors. J App Pharm Sci. 2014;4(11):117-27.

10. Gupta SK. Post marketing surveillance. Text book of Pharmacovigilance, First edition, Jaypee Brothers Medical Publishers (P) Ltd. 2011;75.

11. Gupta YK. Ensuring patient safety-launching the new pharmacovigilance programme of India. Pharma Times. 2010;42(8):21-6.

12. Rehan HS, Vasudev K, Tripathi CD. Adverse drug reaction monitoring: the knowledge, attitude and the practices of the medical students and the prescribers. Natl Med J India. 2002;15(1):24-6.

13. Desai, Iyer G, Panchal J, Shah S, Dikshit RK. An evaluation of the knowledge, attitude and the practice of adverse drug reaction reporting among the prescribers at a tertiary care hospital. Perspective in Clinical Research. 2011;2(4):129-35.

14. Gupta P, Udupa A. Adverse drug reaction reporting and pharmacovigilance: knowledge, attitudes and perceptions among the resident doctors. J Pharm Sci Res. 2011;3:1064-9.

15. Vora MB. Knowledge on the adverse drug reactions and the pharmacovigilance activity among the undergraduate medical students of Gujarat. IJPSR. 2012;3(5):1511-5.

Cite this article as: Laila KV, Hemalatha $\mathrm{T}$. Awareness of adverse drug reactions reporting among doctors in a tertiary care centre. Int J Basic Clin Pharmacol 2016;5:2236-9. 